\section{A presença feminina nos cursos universitários e nas pós-graduações: desconstruindo a idéia da universidade como espaço masculino}

\section{Women's presence in undergraduate and graduate courses: deconstructing the idea of university as a male domain}

GUEDES, Moema de Castro. A presença feminina nos cursos universitários e nas pós-graduações: desconstruindo a idéia da universidade como espaço masculino. História, Ciências, Saúde - Manguinhos, Rio de Janeiro, v.15, supl., p.117-132, jun. 2008.

A entrada das mulheres nas universidades na recente história brasileiraé um marco das mudanças em curso em nossa sociedade. A presente análise contextualiza o contingente populacional com curso universitário no Brasil e ressalta as continuidades e rupturas da participação de homens e mulheres nesse espaço. Baseada nos últimos quatro Censos do IBGE, a análise revela que em trinta anos as mulheres conseguiram reverter o quadro de desigualdade histórica e consolidar uma nova realidade em que são maioria (60\%) dos formados entre os mais jovens. A comparação entre o contingente de indivíduos com nível universitário em 1970 e 2000 revela, também, expressiva entrada feminina em cursos tradicionalmente masculinos.

Palavras-chave: educação; relações de gênero; ensino universitário; Brasil.

GUEDES, Moema de Castro. Women's presence in undergraduate and graduate courses: deconstructing the idea of university as a male domain.

História, Ciências, Saúde - Manguinhos, Rio de Janeiro, v.15, Suppl., p.117-132, June 2008.

Women's entrance into the university in recent Brazilian history is a sign of the changes underway in our society. The present analysis takes the slice of the population that holds a university diploma and contextualizes it within the broader process of boosting enrollment at Brazilian schools, while emphasizing continuities and ruptures in the pattern of male and female participation in this arena. Based on the last four IBGE censuses, our analysis reveals that in thirty short years women have managed to reverse a picture of historical inequality and to solidify a new reality in which they are the clear majority (60\%) of college graduates in younger cohorts. A comparison between those holding university degrees in 1970 and in 2000 shows a significant entrance of women into traditionally male courses.

Keywords: education; gender relations; university teaching. 
$\mathrm{O}$ pano de fundo das questões que pretendemos analisar no presente artigo é o processo de democratização - ainda em curso - do acesso da população brasileira aos diferentes níveis de educação. Destacado como marco histórico do período em questão, foi esse processo que possibilitou a formação de um expressivo contingente populacional que chega a completar o ensino médio e, desse modo, ocasionar aumento de demanda pelo nível universitário no Brasil.

A expansão da escolaridade no Brasil - assim como o aumento do número de vagas oferecidas nas universidades desde a década de 1970 - foi um fenômeno observado em maior intensidade no contingente populacional feminino. Nesse curto período, as mulheres conseguiram reverter um quadro de desigualdade histórica e consolidar uma nova realidade, em que são mais escolarizadas que o contingente masculino.

O recorte da população de nível universitário reflete o quanto a mudança foi rápida e marcante. Nessa perspectiva, a análise geracional e o olhar específico para a entrada feminina em cada curso universitário revelam diferenciações históricas fundamentais nos tipos de inserção social das mulheres no contexto brasileiro.

\section{O recente processo de escolarização da população brasileira}

Nas últimas três décadas, a população brasileira vivenciou um processo de intensa escolarização, que modificou significativamente sua composição em todos os níveis educacionais. ${ }^{1}$ As principais mudanças ocorridas relacionam-se à expansão do contingente que chega a completar o ciclo fundamental $\left(1^{\circ} \mathrm{grau}\right)$ e o ensino médio ( $2^{\circ}$ grau). Esse aumento também é verificado, ainda que em menor escala, na proporção de indivíduos que finalizaram o curso universitário. De modo geral, podemos afirmar ter sido na década de 1970 que uma distribuição relativa da população brasileira por estratos de escolaridade começa a modificarse acentuadamente, dando início a um processo que ainda se desenvolve. ${ }^{2} \mathrm{O}$ crescimento da escolaridade é uma tendência verificada em todas as décadas seguintes.

A questão da alfabetização maciça da população - inclusive de adultos - e a dimensão cada vez mais central que a política de atenção à freqüência de crianças às escolas veio tomando na ação governamental foram condições fundamentais para a melhora nos índices aqui apontados. Como observam Beltrão e Novellino (2002), a taxa bruta de alfabetização da população acima de cinco anos aumentou substancialmente (chegando a dobrar) desde a década de 1940 até os dias de hoje, em que mais de $80 \%$ dos brasileiros são alfabetizados.

A análise do quadro geral de evolução da escolaridade para a presente pesquisa representa um recorte mais amplo, que pretende contextualizar nosso foco central: o contingente populacional com nível universitário. A comparação da trajetória desse grupo em relação aos outros estratos de escolaridade constitui tarefa importante para futuras análises.

Um aspecto a ser destacado é que, para fins de comparação, trabalhamos apenas com indivíduos de 20 anos ou mais - idade mínima em que, teoricamente, qualquer indivíduo poderia ter concluído o nível superior. Desse modo, descartamos o peso das crianças e jovens que possuem um nível educacional mais baixo devido à própria etapa de escolarização a que corresponde sua idade. 
O Gráfico 1 apresenta a composição da população brasileira com mais de vinte anos, por último curso concluído. ${ }^{3}$ É importante destacar que o cálculo do peso relativo que cada grupo de escolaridade tinha no momento do Censo Demográfico ${ }^{4}$, neste caso, não inclui indivíduos que nunca freqüentaram a escola. A exceção é o Censo de 1980, segundo o qual os indivíduos que chegaram a ir à escola (sem, contudo, completar o primeiro ano) são contabilizados com os que chegaram a completar um ano de estudo. Essa mudança metodológica resultou em aumento do peso relativo do contingente sem nenhum curso concluído nesse ano. Por essa razão, ignoramos esses diferenciais em nossa análise.

Gráfico 1 - Distribuição da população brasileira com mais de 20 anos, por curso concluído

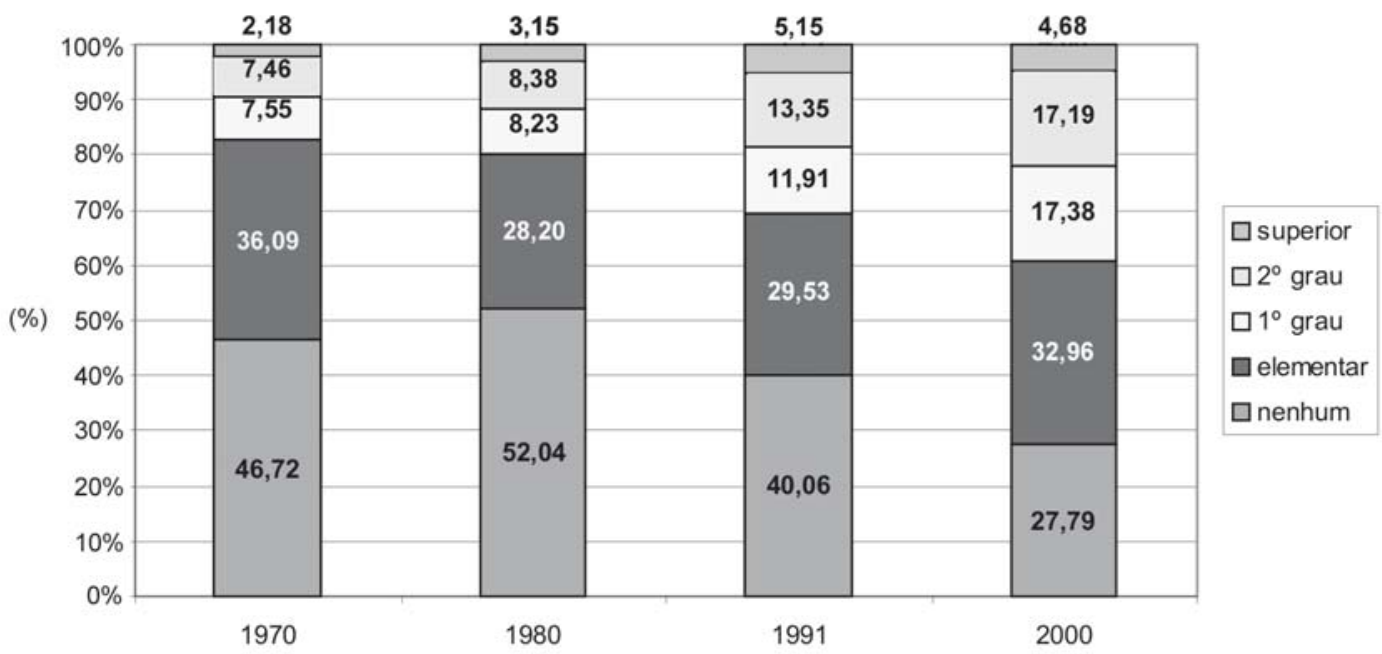

Fonte: Censos Demográficos de 1970, 1980, 1991 e 2000 do Instituto Brasileiro de Geografia e Estatística (IBGE). Elaboração própria.

Como ilustra o Gráfico 1, o principal marco do processo de escolarização observado nos últimos trinta anos no Brasil foi a queda do contingente populacional que não chega a concluir nenhum curso (diferença de 19\%). A grande redução desse contingente, apresentada principalmente na década de 1990, foi fruto de desdobramentos da Constituição de 1988, que conferiu papel de grande destaque à educação nas políticas governamentais, e de uma nova conjuntura internacional que, através de um movimento de diversos atores sociais (principalmente organizações multilaterais), veio apontando a educação como estratégia fundamental para a redução de desigualdades econômicas e sociais nos mais diversos âmbitos. Nesse contexto, as estatísticas produzidas em nível nacional acerca do desempenho dos estudantes, bem como a verificação dos níveis educacionais da população brasileira transformaram-se em indicadores que mensurariam o comprometimento do governo com as políticas educacionais que impulsionariam o Brasil na "agenda mundial para o desenvolvimento".${ }^{5} \mathrm{O}$ principal reflexo desse tipo de preocupação foi uma política centrada na melhora das estatísticas ${ }^{6}$, o que gera necessidade de relativização dos números por meio de trabalhos que enfoquem essa realidade de modo mais qualitativo. 
A oscilação do grupo que completou o ensino elementar (também chamado primário), e sua pequena variação no período em questão podem ser analisadas como aspectos positivos, por tratar-se de uma escolarização muito baixa. Os grandes diferenciais que refletem o salto de escolaridade da população brasileira ocorrem no contingente populacional que consegue finalizar o $1^{\circ}$ e o $2^{\circ}$ graus. Esse avanço possibilita a oferta potencial de uma parcela maior da população para as universidades - processo que cresce gradualmente em todas as décadas, em especial na de 1980. É importante destacar que todos os grupos crescem em termos absolutos, mas seu peso em relação à população total às vezes é menor - caso do contingente que chega a completar o nível superior na década de $1990 .^{7}$

Em relação ao grupo com nível superior, apesar do pequeno aumento de peso em relação à população total, destaca-se seu crescimento interno (percentual relativo dobrado) como importante marca da dinâmica educacional brasileira nesse recente período histórico. A política governamental de franca expansão das universidades federais e estaduais, na década de 1970, e o crescimento do ensino privado nesse segmento, nos anos 80 e 90, fizeram que a mão-de-obra brasileira se tornasse mais qualificada para o mercado de trabalho em curto período. Essa tendência também se verificou na expansão das pós-graduações e na formação de grupos de pesquisa nas universidades federais, através da criação de planos de carreiras de pesquisador e do fomento de bolsas de estudo.

A crescente procura das camadas médias por cursos de nível superior, nos anos 70, é apontada por Cunha (1975) como fruto de uma lógica vigente, que substituía a ascensão social mediante poupança e investimento pela ascensão proporcionada pelo sistema educacional. Essa demanda foi concomitantemente responsável pelo crescimento diferencial por cursos e entidades. Outro fator determinante desse processo, ressaltado pelo autor, é o aumento da procura feminina por esse tipo de ensino.

Do ponto de vista geral do rendimento escolar diferenciado entre homens e mulheres, Rosemberg (2001) aponta a proporção ligeiramente superior de estudantes homens no sistema de ensino como resultado de uma trajetória mais lenta - maior tempo para percorrer trajeto equivalente - que a feminina. Além disso, a autora destaca a segmentação sexual dos ramos de ensino como uma tendência que ocorre tão precocemente quanto o sistema escolar permite. Ou seja, as 'habilidades intrínsecas' de homens e mulheres são atributos que vão sendo construídos e reforçados desde o início do processo de escolarização.

A questão do rendimento escolar diferenciado e a concentração feminina em cursos secundários propedêuticos, ao passo que os homens agrupam-se nos cursos profissionais ${ }^{8}$, são importantes indícios de que a educação, entendida em seu sentido mais amplo, desempenha papel fundamental na naturalização dos papéis femininos e masculinos. A idéia de que as meninas teriam mais propensão às artes e à literatura (facilidade nas disciplinas articuladas à sensibilidade e emoção), enquanto os meninos apresentariam mais aptidão nas ciências, devido a sua maior racionalidade, permeia o imaginário coletivo dos espaços escolares. Esse tipo de visão acaba se convertendo em uma espécie de profecia auto-realizável, em que todos os casos 'desviantes' não são devidamente estimulados. Essa tendência tem reflexos fundamentais na segmentação ocupacional observada nos cursos universitários, tema do nosso terceiro tópico. 


\section{A trajetória do contingente feminino com nível universitário}

O contexto social em que ocorre a expansão do ensino superior é marcado pela abertura do regime político ditatorial, pela liberalização sexual e pela quebra de antigos 'tabus'. O movimento feminista começa a ressurgir no Brasil e a entrada das mulheres no mercado de trabalho aparece também nas classes mais altas, nas quais tradicionalmente o papel desempenhado pelo contingente feminino estava ligado ao espaço doméstico e aos afazeres do lar. Essas mudanças são de suma importância para o espaço ocupado pelas mulheres no processo de escolarização da população brasileira.

A questão fundamental, para a análise que pretendemos desenvolver, centra-se nos diferenciais desse processo para homens e mulheres. Como mostraremos a seguir, a melhora nos níveis educacionais foi substancialmente maior para o contingente feminino ${ }^{9}$, especificamente as coortes mais jovens que estavam em idade escolar em cada período e no grupo de universitárias. Esses grupos foram os principais responsáveis pelo aumento total apontado no gráfico anterior.

O ensino universitário se destaca no processo mais amplo de escolarização feminina como um importante marco pois sempre esteve mais diretamente relacionado à maior presença no mundo público e à aquisição não apenas de habilidades para o mercado de trabalho, mas também de novos valores e práticas. A importância dessa questão na estruturação de relações de gênero mais equânimes se reflete no fato de que, historicamente, essa foi uma bandeira que uniu as diversas correntes do movimento feminista. Perrot (2007) sintetiza essa dimensão ao afirmar que "o direito ao saber, não somente à educação mas à instrução, é certamente a mais antiga, a mais constante, a mais largamente compartilhada das reivindicações [do movimento feminista]. Porque ele comanda tudo: a emancipação, a promoção, o trabalho, a criação, o prazer" (p.159).

De modo mais pragmático, a análise da trajetória do contingente feminino com nível universitário é fundamental, uma vez que o acesso às universidades traduz-se em ascensão social e possibilidade de concorrência por melhores postos de trabalho e, do ponto de vista das relações de gênero, em ocupação de postos de poder/comando controlados tradicionalmente por homens. Essa perspectiva torna-se ainda mais relevante em um contexto como o brasileiro, no qual a participação feminina em importantes esferas decisórias ainda é bastante incipiente. Como aponta Valenzuela (2000), em relação a outros países latinoamericanos, se, por um lado temos uma boa taxa de participação feminina no mundo do trabalho, por outro estamos muito mal colocados no ranking do IPG, o Índice de Potenciação de Gênero, desenvolvido pelo Programa das Nações Unidas Para o Desenvolvimento (PNUD) para medir a desigualdade de gênero em esferas-chaves da participação econômica e política e nas instâncias decisórias.

Outro fator que consolida o grupo selecionado como objeto relevante para as análises de gênero é a relação direta, no caso das mulheres brasileiras, entre escolaridade e participação no mercado de trabalho. Nesse sentido, Soares e Isaki (2002) apontam o aumento do nível educacional feminino como a grande variável que explica 59\% do aumento da participação das mulheres entre o período de 1977 e 2001, coberto pelas Pesquisas Nacionais de Amostra Domiciliar (PNADs). Essa tendência evidencia tal grupo de escolaridade como o que apresenta menores diferenciais de participação em relação aos homens. 
A intensa associação entre escolaridade e participação das mulheres no mercado de trabalho ocorre não apenas porque o mercado é mais receptivo ao trabalhador mais bem qualificado de modo geral, mas também porque esse grupo pode contar com atividades mais gratificantes e bem remuneradas, que compensam os gastos com a infra-estrutura doméstica necessária para suprir sua saída do lar (Bruschini, 2000).

A análise da variável 'último curso concluído' nos grupos etários revela importantes aspectos. O comportamento padrão verificado costuma ser o de coortes que mantêm, ao longo da vida, uma composição de estratos educacionais muito semelhante ao momento em que tinham por volta de 30 anos. Ou seja, o contingente populacional que retorna aos estudos após essa idade não é proporcionalmente expressivo dentro da população. Outro aspecto importante é que as mudanças verificadas ao longo desse processo, em razão de sua intensidade e rapidez, fizeram que, dentro da mesma população, os jovens e adultos fossem muito mais escolarizados que os idosos. Nesse contexto, o peso das coortes mais antigas mascara a magnitude do fenômeno, focado principalmente no contingente populacional em idade escolar ou recém-formado.

Desse modo, a análise geracional, em especial a dos grupos etários que compõem o início da vida adulta (25 a 29 anos), possibilita uma melhor visualização das continuidades, rupturas e tendências do processo de escolarização da população brasileira no período. A comparação entre gerações também capta importantes elementos desse processo, para a perspectiva central da presente pesquisa: o enfoque de gênero. O Gráfico 2 retrata as mudanças mais acentuadas (em relação à população total) na composição educacional de homens e mulheres com 25-29 anos.

A análise isolada desse grupo mais jovem revela importantes diferenciações em relação ao primeiro gráfico, no qual constava a população total. O grupo sem nenhum curso concluído é menor, e o contingente que chega a completar o $1^{\circ}$ e o $2^{\circ}$ graus é maior. Sobre o quadro geral apresentado no Gráfico 2, destacamos que, já nos anos 70, a distribuição de

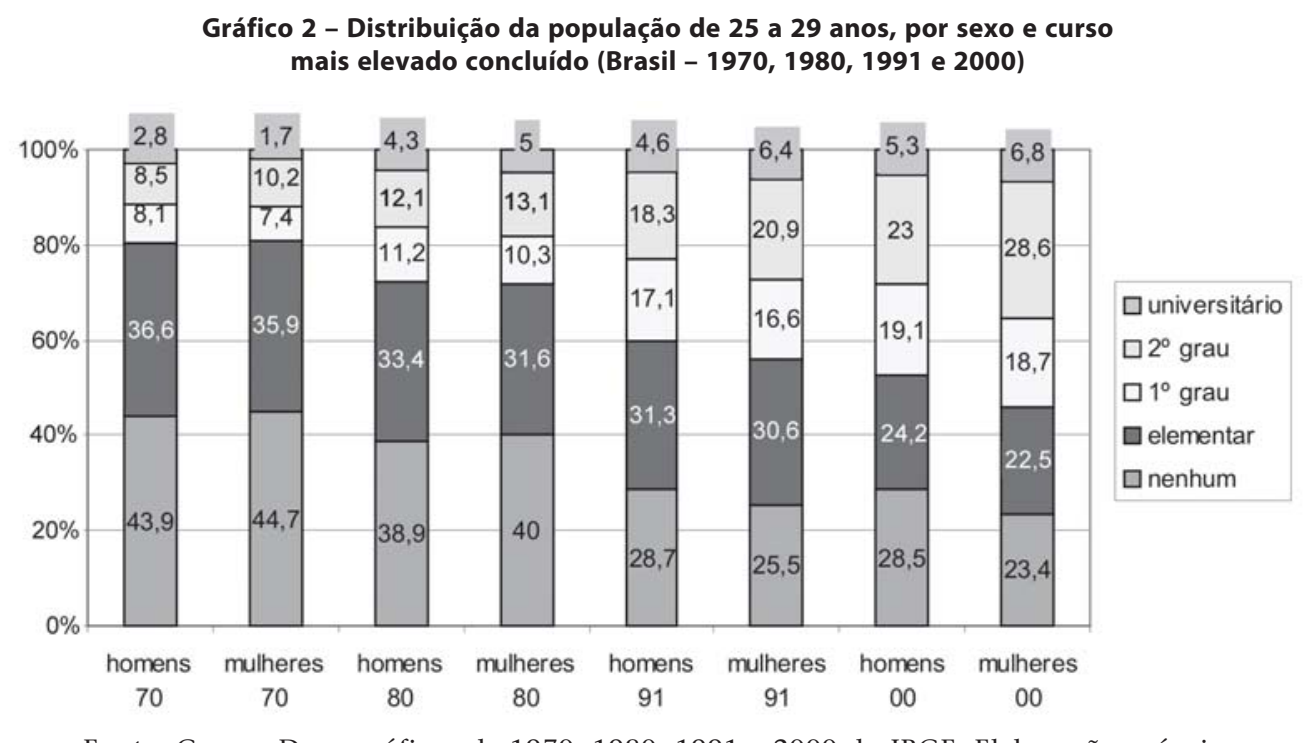

Fonte: Censos Demográficos de 1970, 1980, 1991 e 2000 do IBGE. Elaboração própria. 
estratos de escolaridade entre homens e mulheres de 25-29 anos não é muito diferente, com exceção do contingente com nível universitário. A maior concentração feminina no estrato com $2^{\circ}$ grau completo, na década de 1970, indica um freio no processo de escolarização: ao passo que uma parcela expressiva dos homens que concluem o $2^{\circ}$ grau ingressa na universidade, um contingente muito mais reduzido de mulheres dá continuidade aos estudos. ${ }^{10}$ Esse diferencial é um dos fatores, como foi apontado anteriormente, de crescimento da demanda por mais vagas no ensino superior.

Barroso e Mello (dez. 1975) destacam um fator fundamental para a clara estratificação baseada no sexo, existente na clientela potencial do ensino superior na década de 1970: a altíssima proporção de mulheres no curso normal. No período estudado pelas autoras, 1955 a 1970, o percentual de mulheres concluintes do colegial que cursaram essa modalidade não variou, mantendo-se constantemente por volta de $63 \%$ do total de formandas. Essa opção tornava mais difícil seu acesso às universidades, uma vez que o conteúdo exigido nas provas de vestibular baseava-se em disciplinas lecionadas nos chamados ensino secundário científico e ensino secundário clássico, cursados majoritariamente por meninos. Nesse contexto, as meninas que quisessem ingressar em uma universidade eram duplamente desestimuladas: primeiramente eram pressionadas, pela tradição feminina, a cursar o Normal (o que lhes conferia uma profissão que não exigia maiores estudos), e posteriormente, quando desejavam ingressar nas universidades, enfrentavam a necessidade de estudos complementares em cursinhos, a fim de poderem contar com conteúdos nunca antes estudados em sua vida escolar.

Apesar dessas limitações, o crescente contingente populacional feminino que concluiu o $2^{\circ}$ grau nos anos 70 começou a ingressar nas universidades por meio de um processo característico desse período: a crescente participação concentrada em carreiras que preparavam para o magistério secundário, em especial a área de ciências humanas e letras. Como tal estratégia, as mulheres, por um lado, reproduziam o estereótipo vigente da 'ocupação adequada para a mulher' e cumpriam a expectativa, construída socialmente, de continuarem sendo professoras e, por outro, resolviam seu problema estrutural de falta de preparo para o vestibular, uma vez que esses eram os cursos menos concorridos.

A demanda feminina por cursos universitários que possibilitassem a formação de professores do ensino secundário acabou por marcar a própria dinâmica de crescimento do ensino superior no Brasil. A intensa procura por esse tipo de serviço gerou uma expansão desigual das vagas disponibilizadas em cada curso pelo governo, por um lado, e o crescimento da oferta de vagas no ensino superior privado, por outro (Cunha, 1975).

O salto quantitativo em relação à parcela da população jovem de mulheres (25-29 anos) que concluiu o curso superior nos anos 70 foi enorme: em apenas dez anos esse contingente triplicou. O ritmo de crescimento continuou alto nas décadas seguintes (muito superior ao masculino), mas deixou de ser tão intenso quanto no período inicial.

Outro aspecto importante a ressaltar é que o percentual de mulheres no grupo etário 25-29 anos com $2^{\circ}$ grau completo, no Censo Demográfico 2000, é consideravelmente maior que o de homens. Essa diferença de cinco pontos percentuais sugere que, no futuro, caso desejem cursar uma universidade, muito mais mulheres do que homens estarão prontamente aptas a fazê-lo. 


\section{Alguns aspectos da reversão do hiato de gênero}

A tradição da universidade como um espaço masculino foi marcantemente rompida na década de 1970, quando a entrada feminina nesse reduto foi tão intensa que, já no Censo Demográfico de 1980, as mulheres de 25-29 anos com nível universitário eram 5\% porcentagem superior à masculina no mesmo grupo etário. A análise da trajetória desse grupo levanta importantes aspectos. Enquanto os homens expressam, no contingente universitário, um aumento de peso relativo semelhante ao dos outros estratos de escolaridade, o aumento de peso relativo, no caso das mulheres, é muito mais expressivo, chegando a quase triplicar nos últimos trinta anos. O Gráfico 3 ilustra a rapidez com que, de minoria (em 1970), as mulheres passam, apesar do peso das coortes mais antigas, a maioria (em 2000) do contingente com nível superior no Brasil.

A melhora nos índices de escolaridade das mulheres pode ser percebida em todos os níveis educacionais, porém mais intensamente no grupo com nível superior, estrato no qual apenas $25 \%$ eram mulheres em 1970, mas que no ano 2000 passa a ser majoritariamente feminino (53\%). O significado desse avanço na maior qualificação das mulheres representa uma conquista, independentemente da maneira como essa melhora na escolaridade repercutiu na inserção laboral feminina.

Gráfico 3 - Distribuição da população total com nível universitário, por sexo (Brasil 1970, 1980, 1991 e 2000)

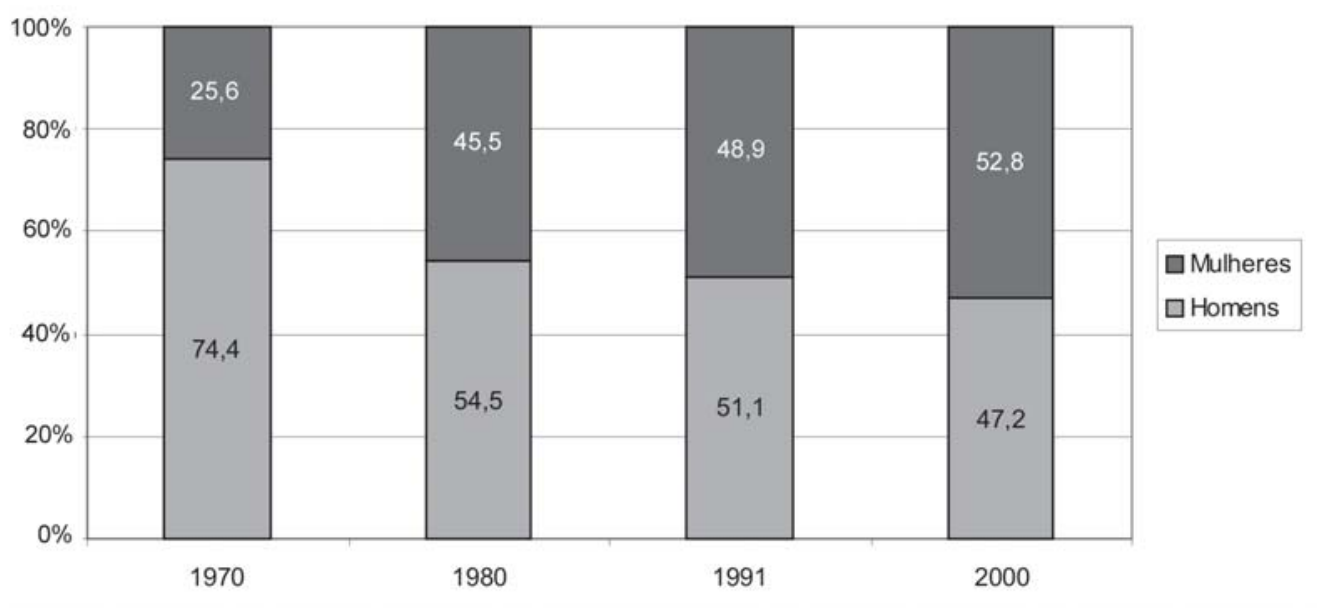

Fonte: Censos Demográficos de 1970, 1980, 1991 e 2000 do IBGE. Elaboração própria.

Mais uma vez a análise por coorte possibilita o levantamento de importantes questões. A tendência verificada, já na década de 1970, de sólida entrada de mulheres jovens, que acabaram de concluir o segundo grau, nas universidades em maior percentual que homens se consolidou nesses últimos trinta anos e não parou de crescer. O Gráfico 4 mostra a diferença entre homens e mulheres em cada geração, no momento atual.

Percebe-se claramente, no Gráfico 4, uma tendência à inversão: enquanto, na coorte mais velha, de cada cinco indivíduos com nível superior três são homens e dois são mulheres, 
na coorte mais nova a proporção é de três mulheres para dois homens. Esse diferencial, do ponto de vista simbólico, representa importantes mudanças, ressaltadas por tratar-se de gerações que coexistem no mesmo período histórico. Em relação aos percentuais do grupo etário com sessenta anos ou mais, faz-se necessária uma relativização dos dados, uma vez que as mulheres têm uma expectativa de vida maior que a dos homens, o que lhes confere um peso maior que o masculino.

Gráfico 4 - Distribuição da população com nível universitário, por sexo e grupo etário (Brasil - 2000)

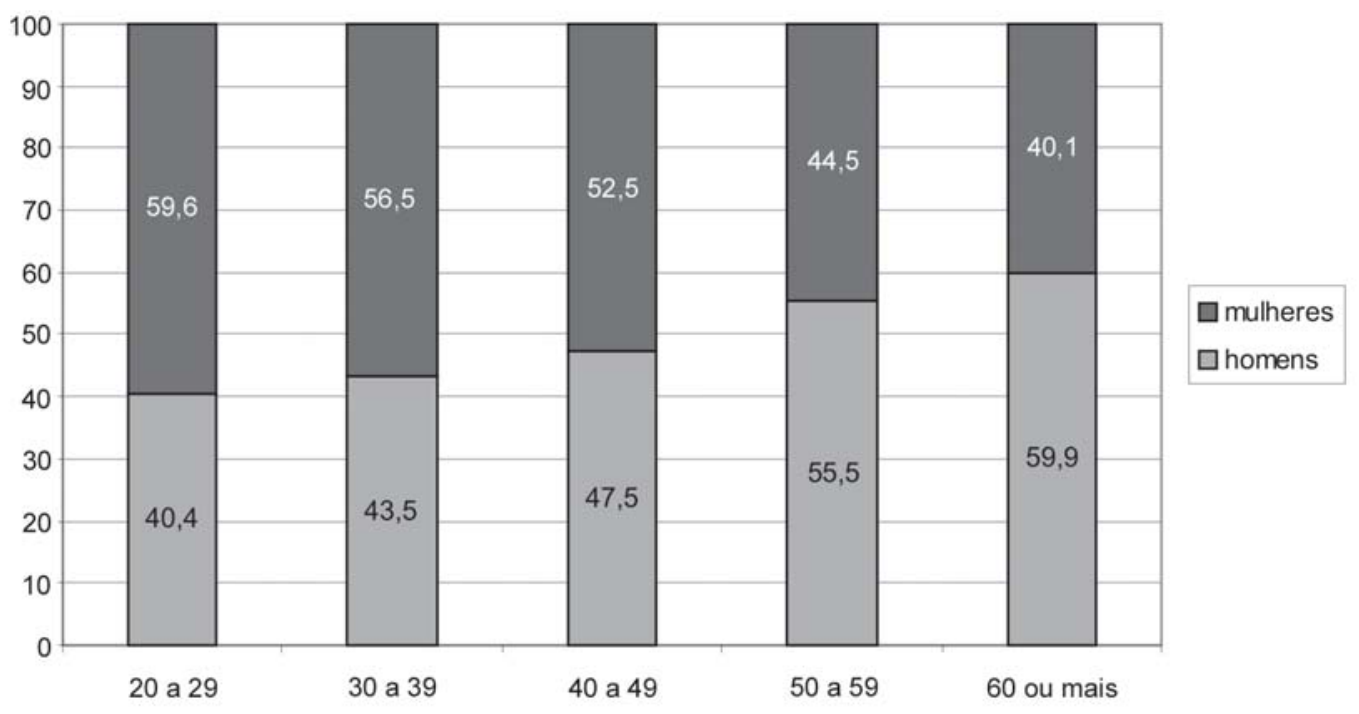

Fonte: Censo Demográfico de 2000 do IBGE. Elaboração própria.

A principal questão que essa análise geracional levanta é que, nas coortes mais novas, o hiato de gênero não apenas foi superado, do ponto de vista dos indivíduos que chegam a concluir um curso universitário, mas ultrapassou os limites do equilíbrio e agora tende a um distanciamento favorável às mulheres. ${ }^{11} \mathrm{O}$ diferencial de $20 \%$ entre as populações feminina e masculina de nível universitário com 20 a 29 anos é um dado que provavelmente apresentará, futuramente, conseqüências tanto no mercado de trabalho quanto no fortalecimento do poder das mulheres de forma mais ampla.

O intenso avanço do ponto de vista quantitativo, contudo, mascara alguns aspectos de exclusão e segmentação do processo de entrada das mulheres nas universidades. Igualdade numérica não significa eqüidade de gênero, uma vez que a tendência de maior peso feminino nas carreiras de menor prestígio e mais mal remuneradas se acentua ao longo do período. No entanto, como mostram os dados, esse processo está lentamente se modificando. A Tabela 1 refere-se à população que completou cada um dos cursos listados ${ }^{12}$ nos Censos de 1970 e 2000 no Brasil. ${ }^{13 .}$

Um primeiro aspecto fundamental, demonstrado nos dados da Tabela 1, é que se acentua o padrão - verificado já no Censo de 1970 - de concentração feminina nos cursos universitários que representam majoritariamente atuação articulada ao magistério ou à 
atenção e ao cuidado de alguns segmentos sociais. Ou seja, com o acréscimo do contingente populacional que se forma nos últimos trinta anos do século XX e é captado no Censo de 2000, percebemos que não houve uma masculinização das ocupações voltadas para a chamada economia do cuidado, mas, pelo contrário, elas se tornam ainda mais femininas.

O dado mais importante expresso na Tabela 1 é que em praticamente todos os cursos em que a presença feminina é minoritária, as mulheres apresentam um avanço expressivo na proporção de formados em 2000. ${ }^{14}$ As únicas exceções em que o contingente feminino não chega a alcançar 30\% dos formados são os cursos de agronomia e todos os tipos de engenharia. Se, por um lado, acentua-se a tendência de permanência das mulheres nos segmentos menos valorizados no mercado de trabalho, por outro a expansão da participação feminina em todas as carreiras é um fenômeno que não pode ser ignorado. Outro elemento importante destacado na Tabela 1 são os cursos em que o crescimento da presença feminina foi tão intenso que, mesmo diante do peso das coortes mais antigas, o percentual de formados do sexo feminino já supera o de homens. Alguns cursos criados recentemente, de grande prestígio social (vestibular concorrido), também se destacam pela majoritária presença de mulheres no contingente de formados no Censo 2000 - é o caso das carreiras de comunicação social (64\% de mulheres) e biologia (76\% de mulheres). ${ }^{15}$

\begin{tabular}{|c|c|c|c|c|}
\hline Cursos universitários* & $\begin{array}{c}1970 \\
\text { Mulheres (\%) }\end{array}$ & $\begin{array}{c}1970 \\
\text { Homens (\%) }\end{array}$ & $\begin{array}{c}2000 \\
\text { Mulheres (\%) }\end{array}$ & $\begin{array}{c}2000 \\
\text { Homens (\%) }\end{array}$ \\
\hline Engenharia mecânica & 2 & 98 & 3 & 97 \\
\hline Engenharia elétrica & 2 & 98 & 7 & 93 \\
\hline Engenharia civil & 2 & 98 & 15 & 85 \\
\hline Agronomia & 3 & 97 & 12 & 88 \\
\hline Veterinária & 4 & 96 & 30 & 70 \\
\hline Física & 39 & 61 & 30 & 70 \\
\hline Economia & 9 & 91 & 32 & 68 \\
\hline Medicina & 11 & 89 & 36 & 64 \\
\hline Administração & 15 & 85 & 39 & 61 \\
\hline Direito & 13 & 87 & 40 & 60 \\
\hline Química & 39 & 61 & 44 & 66 \\
\hline Estatística & 17 & 83 & 47 & 53 \\
\hline Odontologia & 18 & 82 & 51 & 49 \\
\hline Arquitetura & 17 & 83 & 54 & 46 \\
\hline Educação física & 55 & 45 & 54 & 46 \\
\hline Filosofia & 66 & 34 & 55 & 45 \\
\hline Matemática & 39 & 61 & 60 & 40 \\
\hline Farmácia & 32 & 68 & 65 & 35 \\
\hline Geografia & 69 & 31 & 72 & 28 \\
\hline História & 66 & 34 & 74 & 26 \\
\hline Belas artes & 71 & 29 & 75 & 25 \\
\hline Ciências sociais & 72 & 28 & 78 & 22 \\
\hline Letras & 73 & 27 & 87 & 13 \\
\hline Psicologia & 70 & 30 & 89 & 11 \\
\hline Enfermagem & 93 & 7 & 91 & 9 \\
\hline Pedagogia & 84 & 16 & 93 & 7 \\
\hline Serviço social & 90 & 10 & 98 & 2 \\
\hline
\end{tabular}

* Listados em ordem crescente, segundo a proporção da presença feminina no Censo 2000.

Fonte: Censos Demográficos de 1970 e 2000 do IBGE. Elaboração própria. 
As mudanças expressas na Tabela 1 contrastam com as análises sobre a presença feminina na universidade, na década de 1970. Lewin (fev. 1980) focaliza a participação da mulher na força de trabalho brasileira, observando sua distribuição pelas diversas ocupações, seu salário em relação ao salário masculino e suas opções pelas diversas carreiras do ensino superior. A autora discute a problemática do trabalho feminino em termos da dinâmica da sociedade capitalista, para a qual, segundo ela, a utilização de mulheres em ocupações de menor prestígio e remuneração seria altamente funcional. Em que pesem as importantes mudanças sofridas pelo próprio capitalismo (dimensão que não é foco do presente artigo), os resultados empíricos das tabulações censitárias demonstram que as mulheres não estariam mais restritas às ocupações de menor prestígio e remuneração. Essa seria uma ruptura histórica importante para a análise das relações de gênero.

Porém a opção feminina por continuar estudando mais tempo pode estar relacionada à falta de alternativas no mercado de trabalho. Do ponto de vista masculino, o abandono do curso universitário provavelmente se articula à necessidade de trabalhar, ou seja, à representação tradicional do homem como provedor da família. Um reflexo dessa tendência é o fato de os cursos de mestrado e doutorado serem um reduto feminilizado, fato que se reflete na presença sempre mais ampla de mulheres do que a distribuição apresentada anteriormente nos cursos de graduação.

A análise histórica do diferencial de participação de homens e mulheres nesse âmbito universitário não pôde ser realizada porque apenas a partir do Censo de 1991 o IBGE passou a categorizar separadamente os indivíduos que concluíram apenas a graduação daqueles que concluíram pós-graduações. Por essa razão, optamos por trabalhar separadamente esse contingente no Censo 2000, expresso na Tabela $2 .{ }^{16} \mathrm{Em}$ busca de uma análise mais ancorada nos diferenciais históricos e geracionais do processo, separamos a população total da população de 20 a 29 anos.

$\mathrm{O}$ avanço da presença feminina no contingente populacional que conclui mestrado ou doutorado ${ }^{17}$ na coorte mais jovem verifica-se mais intensamente nas áreas em que as mulheres

Tabela 2 - Distribuição do contingente de formados, por sexo e área de mestrado/doutorado, na população total e na população de 20 a 29 anos (Brasil - 2000)

\begin{tabular}{lcccc} 
& \multicolumn{2}{c}{ População total } & População de 20 a 29 anos \\
\cline { 2 - 5 } Áreas de mestrado ou doutorado & $\begin{array}{c}\text { Participação } \\
\text { feminina (\%) }\end{array}$ & $\begin{array}{c}\text { Participação } \\
\text { masculina (\%) }\end{array}$ & $\begin{array}{c}\text { Participação } \\
\text { feminina (\%) }\end{array}$ & $\begin{array}{c}\text { Participação } \\
\text { masculina (\%) }\end{array}$ \\
\hline Ciências agrárias & 30 & 70 & 46 & 54 \\
Medicina & 34 & 66 & 57 & 43 \\
Outras ciências biológicas/saúde & 58 & 42 & 71 & 29 \\
Engenharia & 18 & 82 & 35 & 65 \\
Outras ciências exatas & 35 & 65 & 43 & 57 \\
Administração & 28 & 72 & 46 & 54 \\
Ciências econômicas e contábeis & 27 & 73 & 44 & 56 \\
Direito & 32 & 68 & 93 & 47 \\
Pedagogia & 83 & 17 & 60 & 10 \\
Outras ciências humanas & 60 & 40 & 77 & 40 \\
Letras e artes & 75 & 25 & & 23 \\
\hline
\end{tabular}

Fonte: Censo Demográfico 2000 do IBGE. Elaboração própria. 
são minoria (os tradicionais redutos femininos continuaram com uma distribuição por sexo semelhante, na nova geração de formados), o que reforça a idéia do campo acadêmico como um setor que vem se feminilizando nas áreas mais masculinizadas. Contudo percebemos um pequeno aumento do peso masculino no mestrado e doutorado de carreiras femininas na graduação: administração, direito, pedagogia e letras (letras e artes).

Apesar de a conclusão de um curso de mestrado ou doutorado não representar diretamente melhores salários no mercado de trabalho e de ser um nicho ocupacional cada vez mais procurado diante da escassez de empregos, mesmo para uma mão-de-obra qualificada como a que estamos analisando, o acesso crescente das mulheres a esses espaços representa um avanço, se considerarmos a educação como um bem intrínseco estruturador de novas relações de poder.

\section{As diferenças geracionais}

O peso das coortes mais velhas e a necessidade de se trabalhar com estratos de idade são evidentes nas análises sobre educação. No caso das pós-graduações, assim como na própria análise quantitativa do contingente feminino que completa o curso universitário, a observação da nova geração de alunos formados nas universidades revela novas trajetórias, tanto no aspecto da continuidade do processo educacional quanto nas escolhas profissionais.

A Tabela 3, que compara as proporções de homens e mulheres na população absoluta com nível universitário e a população com esse mesmo nível educacional de 20 a 29 anos, revela que o avanço da nova geração de mulheres, captado no Censo 2000, não vem sendo apenas quantitativo mas também qualitativo, representado na abertura do leque de carreiras por que as mulheres vêm optando no mercado de trabalho brasileiro.

As mudanças na participação de homens e mulheres em cada carreira universitária, como mostra a Tabela 3, são substanciais, se trabalharmos apenas com esta coorte mais jovem. Em praticamente todas as carreiras há um aumento da participação feminina em relação à população total. ${ }^{18}$ Essa tendência reflete que o processo de intensa entrada feminina nas universidades, na história recente do Brasil, vem perdendo sua característica de segmentação sexual. Ou seja, cada vez mais as mulheres ingressam nas carreiras de maior prestígio social, o que representa uma ruptura com o padrão de inserção das primeiras gerações que concluíram o ensino universitário.

$\mathrm{O}$ fato de os cursos ligados ao magistério terem sido os únicos que apresentaram uma queda na participação feminina no grupo de 20 a 29 anos em relação à população total revela que a distribuição das mulheres pelas carreiras oferecida torna-se cada vez mais heterogênea e concentrada nos cursos concorridos.

A maior diversificação de carreiras para as quais as jovens prestam vestibular e são aprovadas, assim como a perda de prestígio do curso normal ${ }^{19}$ seriam reflexos diretos de mudanças culturais que afetaram a natureza do processo de escolarização de nível superior das mulheres. Essa mudança nas ocupações caminha concomitantemente à persistência de algumas continuidades, mas todas as áreas assiste ao crescimento, maior ou menor, da participação de mulheres (Bruschini, 2000). 
Tabela 3 - Distribuição do contingente de formados, por sexo e curso universitário, na população total e na população de 20 a 29 anos (Brasil - 2000)

\begin{tabular}{|c|c|c|c|c|}
\hline \multirow[b]{2}{*}{ Cursos universitários } & \multicolumn{2}{|c|}{ População total } & \multicolumn{2}{|c|}{ População de 20 a 29 anos } \\
\hline & Mulheres (\%) & Homens (\%) & Mulheres (\%) & Homens (\%) \\
\hline Engenharia mecânica & 3 & 97 & 7 & 93 \\
\hline Engenharia elétrica & 7 & 93 & 12 & 88 \\
\hline Engenharia civil & 15 & 85 & 29 & 71 \\
\hline Agronomia & 12 & 88 & 23 & 77 \\
\hline Veterinária & 30 & 70 & 50 & 50 \\
\hline Física & 30 & 70 & 32 & 68 \\
\hline Economia & 32 & 68 & 51 & 49 \\
\hline Medicina & 36 & 64 & 49 & 51 \\
\hline Administração & 39 & 61 & 54 & 46 \\
\hline Direito & 40 & 60 & 57 & 43 \\
\hline Química & 44 & 66 & 58 & 42 \\
\hline Estatística & 47 & 53 & 49 & 51 \\
\hline Odontologia & 51 & 49 & 66 & 34 \\
\hline Arquitetura & 54 & 46 & 70 & 30 \\
\hline Educação física & 54 & 46 & 63 & 37 \\
\hline Filosofia & 55 & 45 & 38 & 62 \\
\hline Matemática & 60 & 40 & 67 & 33 \\
\hline Farmácia & 65 & 35 & 75 & 25 \\
\hline Geografia & 72 & 28 & 67 & 33 \\
\hline História & 74 & 26 & 72 & 28 \\
\hline Belas Artes & 75 & 25 & 66 & 34 \\
\hline Ciências sociais & 78 & 22 & 70 & 30 \\
\hline Letras & 87 & 13 & 89 & 11 \\
\hline Psicologia & 89 & 11 & 93 & 7 \\
\hline Enfermagem & 91 & 9 & 91 & 9 \\
\hline Pedagogia & 93 & 7 & 95 & 5 \\
\hline
\end{tabular}

Fonte: Censo Demográfico de 2000 do Instituto Brasileiro de Geografia e Estatística (IBGE). Elaboração própria.

\section{Os impactos do processo nas relações de gênero}

Por tratar-se de um período histórico de longa duração, ao longo do qual importantes mudanças socioculturais ocorreram, o processo de entrada feminina nas universidades é marcado também, além da intensidade e rapidez, por mudanças qualitativas importantes a serem destacadas na presente análise.

A mudança fundamental que se desdobra em todas as outras mais diretamente relacionadas ao processo de escolarização refere-se à própria construção das identidades femininas em cada período histórico que a pesquisa abarca. Enquanto a primeira geração de mulheres aqui analisada ainda é profundamente marcada por um sistema patriarcal, que estrutura sua identidade social no papel de mãe e esposa, a geração recém-formada captada no Censo 2000 já vivencia uma realidade em que a participação feminina no mercado de trabalho e o sucesso profissional são encarados como atributos desejáveis e legitimados socialmente.

Barroso e Mello (dez. 1975) ilustram bem a situação vivenciada pelas mulheres universitárias daquele período, estranha aos olhos de hoje: "Além disso, o fato de que a posição social da mulher ainda costuma ser determinada mais pela profissão de seu marido 
do que pela sua própria ocupação parece fazer com que a preocupação com o prestígio e o status não seja para ela, tão dominante na escolha de uma carreira" (p.54).

A entrada das mulheres no mercado de trabalho é freqüentemente destacada como momento fundamental de um novo contexto, no qual identidades femininas menos articuladas ao mundo doméstico emergem e a reestruturação do modelo tradicional de família aparece como marca das mudanças em curso. O papel da educação formal como vetor de ampliação do universo de escolhas das mulheres também é fundamental para a compreensão dessa dinâmica, uma vez que instaura novos desejos e constrangimentos, seja no campo familiar ou no mundo do trabalho. Apesar do desafio que ainda representa a análise da relação ou mesmo da possível causalidade entre esses processos sociais, o papel central da escolarização como elemento explicativo ou vetor de mudanças importantes no campo das relações simbólicas e de poder entre homens e mulheres é, em certa medida, uma questão consensual.

Nesse sentido, o processo de expansão da escolarização em diversos contextos graças a mudanças nas legislações que visaram universalizar o acesso a esse bem, teria consolidado a retirada das mulheres de uma educação predominantemente familiar, na qual os aprendizados eram voltados para seu papel de mãe e esposa, para uma educação voltada para o mundo público. Prost (1992) destaca essa questão ao afirmar que toda educação escolar é educação para a vida pública. Segundo o autor, o aumento geral da escolarização remete a transformações muito mais profundas: "mais do que uma socialização dos aprendizados, seria um aprendizado da sociedade" (p.82).

Atualmente, com a desestruturação do modelo tradicional de família, o papel socialmente construído como feminino continua articulado à maternidade, mas não mais diretamente ao casamento. Nesse contexto a busca das mulheres por uma identidade relacionada ao mercado de trabalho e à esfera profissional vem crescendo, e grande parte do prestígio está condicionada ao seu bom desempenho na vida acadêmica.

Em relação a essas mudanças, chamaríamos a atenção para o papel fundamental de outros processos educativos, que ocorrem concomitantemente com a educação formal (nosso foco) e atuam de forma fundamental na estruturação de novas identidades sociais. Louro (2002) destaca a importância de os educadores alargarem seu âmbito de atuação e exercerem seu ofício na esfera mais ampla da cultura. ${ }^{20}$

\section{Considerações finais}

A abertura do leque de cursos universitários concluídos pela nova geração de mulheres é reflexo de mudanças históricas de natureza dialética. Por um lado, o aparecimento e a difusão de idéias e valores diferentes dos tradicionalmente vigentes acabam por estabelecer novos códigos e práticas no campo das relações sociais, que resultam na crescente opção feminina por carreiras de maior prestígio. Por outro, a efetiva entrada das mulheres nos cursos universitários historicamente masculinos influencia diretamente na construção de novas identidades sociais. Ou seja, o fenômeno reflete um quadro mais amplo de mudanças nas relações de gênero, reforçando-as e estruturando-as ao instaurar novos elementos na realidade social. 
Do ponto de vista mais amplo, a entrada rápida e intensa das mulheres nas universidades, espaços tradicionalmente masculinos, não significa necessariamente uma mudança substancial nas relações de gênero, embora delineie um novo contexto. Se por um lado houve uma 'feminização' do espaço público, por outro o abandono masculino dessas esferas pode apontar uma manutenção de construções sociais tradicionais que continuaram influenciando a prática cotidiana. As pistas para tal questão surgem somente da articulação da variável escolaridade com outras dimensões da vida social, de modo a explicitar de que maneira o título universitário influenciou (ou não) mudanças na inserção dessas mulheres, em especial no mercado de trabalho e, de modo mais geral, em sua identidade. O olhar geracional reflete uma importante dimensão desse processo: as diferenciações internas do próprio grupo de mulheres com nível universitário.

O olhar para a trajetória das mulheres com nível universitário consolida a análise de um grupo que manifesta e reflete contradições do próprio processo de mudança nas relações de gênero na sociedade brasileira, no atual momento histórico: ao mesmo tempo que indica sinais expressivos de novos modelos do feminino (menos articulados exclusivamente ao espaço doméstico), também apresenta traços marcantes de uma cultura patriarcal (ainda) presente em diversas esferas da vida social.

\section{NOTAS}

${ }^{1}$ A decisão política de expansão dos ensinos fundamental e médio é anterior a esse período, mas sua universalização ocorre principalmente a partir da década de 1970. Contudo, o Brasil permanece em desvantagem em relação aos níveis educacionais alcançados por outros países com o mesmo grau de desenvolvimento.

${ }^{2}$ Essa mudança é verificada a partir desse período ao se trabalhar com a população total (peso das coortes mais velhas), uma vez que, analisadas apenas as crianças em idade escolar, ela ocorre anteriormente.

${ }^{3}$ Nesse caso, articulamos duas variáveis captadas no Censo: anos de estudo (para visualização do contingente que não chegou a completar nenhum ciclo) e último curso concluído.

${ }^{4}$ No Censo de 2000 a pergunta relacionada ao último curso concluído foi feita somente para indivíduos não mais estudantes, ou seja, não se captaram aqueles que possuíam o nível universitário e voltaram a estudar, o que pode ter gerado uma sub-representação desse contingente.

${ }^{5}$ Idéia fundamental dos compromissos firmados na última década nas diversas conferências mundiais da ONU e de suas organizações filiadas.

${ }^{6}$ Para tanto, o governo instituiu políticas que assegurassem melhoras imediatas nos índices apresentados. Dois exemplos dessa ação são a aprovação progressiva dos alunos da rede pública e o desenvolvimento de uma série de programas pelos quais a população adulta volta a estudar e adquire os diplomas escolares em um período consideravelmente inferior ao regular.

${ }^{7}$ Essa queda também pode estar relacionada à questão metodológica mencionada anteriormente: a não contabilização de indivíduos que possuem o nível superior, mas voltaram a estudar.

${ }^{8}$ Essa tendência é apontada por Barroso e Mello (dez. 1975) e Rosemberg (2001).

${ }^{9}$ A entrada mais intensa de mulheres nas universidades era previsível, uma vez que existia uma demanda reprimida por parte desse contingente. O fenômeno a que nos referimos aqui é a continuidade desse processo mesmo quando o percentual de homens e mulheres universitários chega a um patamar próximo.

${ }^{10}$ Independentemente da entrada nas universidades nesse período, as mulheres já eram maioria entre os estudantes que chegaram a concluir o segundo grau.

${ }^{11}$ Seria interessante, diante da maior lentidão masculina para concluir os ciclos escolares, apontada pela literatura, uma análise que pudesse responder se os homens estariam postergando a entrada nos cursos 
de graduação ou nas pós-graduações. Contudo, essa informação foge ao escopo do presente artigo por não ser captada nos Censos Demográficos.

12 Alguns cursos de ambos os anos não são citados em razão da pequena proporção de formados na população como um todo.

${ }^{13}$ No Censo de 1970 , os cursos de matemática, física e química e os cursos de engenharia são contabilizados conjuntamente, por isso repetimos as mesmas proporções para todos.

${ }^{14}$ Os únicos cursos em que a participação feminina no contingente de formados diminui, do Censo de 1970 para de 2000, são: física, educação física e filosofia.

${ }^{15}$ Ambos não aparecem na tabela porque não existiam no Censo de 1970.

${ }^{16}$ A população da tabela anterior é formada por indivíduos que cursaram somente a graduação.

17 O IBGE não categoriza separadamente os indivíduos que concluíram mestrado e os que concluíram doutorado.

${ }^{18}$ As exceções são os cursos de geografia, história, belas artes, ciências sociais e serviço social, com pequenas variações, e o curso de filosofia, o único a apresentar uma significativa queda da participação feminina no contingente de formados.

${ }^{19}$ Atualmente apenas uma baixa proporção de meninas, geralmente de classe baixa, cursam o normal.

${ }^{20}$ A linha proposta pela autora se insere em uma perspectiva pós-estruturalista.

\section{REFERÊNCIAS BIBLIOGRÁFICAS}

BARROSO, Carmen Lúcia de M.; MELLO, Guiomar Namo de.

$\mathrm{O}$ acesso da mulher ao ensino superior brasileiro. Cadernos de Pesquisa, São Paulo, n.15, p.47-77. dez. 1975.

BELTRÃO, Kaizô Iwakami; NOVELLINO, Maria Salet.

Alfabetização por raça e sexo no Brasil: evolução no período 1940-2000. Rio de Janeiro: Escola Nacional de Ciências Estatísticas / Instituto Brasileiro de Geografia e Estatística. (Textos para Discussão Ence, 1). 2002.

BRUSCHINI, Cristina.

Gênero e trabalho no Brasil: novas conquistas ou persistência da descriminação? In: Rocha,

Maria Isabel Baltar (Org.). Trabalho e gênero: mudanças, permanências e desafios. São Paulo: Ed. 34. p.13-58. 2000

CUNHA, Luís Antônio C.R.

A expansão do ensino superior: causas e conseqüências. Debate e Crítica, São Paulo, n.5, p.27-58. 1975.

LEWIN, Helena.

Educação e força de trabalho feminino no Brasil. Cadernos de Pesquisa, São Paulo, n.32, p.45-59. fev. 1980.

LOURO, Guacira Lopes.

Gênero: questões para a educação. In:

Bruschini, Cristina; Unbehaum, Sandra G.
(Org.). Gênero, democracia e sociedade brasileira. São Paulo: Fundação Carlos Chagas; Editora 34. p.225-242. 2002.

PERROT, Michelle.

Minha história das mulheres. São Paulo: Contexto. 2007.

PROST, Antoine.

Fronteiras e espaços do privado. In: Prost, Antoine; Vincent, Gerald (Org.). História da vida privada 5: da Primeira Guerra a nossos dias. São Paulo: Companhia das Letras. p.40-143. 1992.

ROSEMBERG, Fúlvia.

Políticas educacionais e gênero: um balanço dos anos 1990. Cadernos Pagu, Campinas, n.16, p.151-198. 2001.

SOARES, Sergei.; ISAKI, Rejane Sayuri. A participação feminina no mercado de trabalho. Rio de Janeiro: Instituto de Pesquisa Econômica Aplicada. (Seminários Dimac, 127). 2002.

VALENZUELA, Maria Elena.

La situación laboral y el acceso al empleo de las mujeres en el Cono Sur. In: Valenzuela, Maria Elena, Reinecke, Gerhard (Org.). ¿Más y mejores empleos para las mujeres?: la experiencia de los países del Mercosur y Chile. Santiago de Chile: Oficina Internacional del Trabalho.

(Documentos OIT). 2000. 